\title{
Las contingencias del patrimonio artístico peruano
}

\author{
Martha Barriga Tello \\ Universidad Nacional Mayor de San Marcos (Lima, Perú)
}

\section{Resumen}

El patrimonio artístico cultural de los países que en algún momento de su historia han sido invadidos o en guerra ha estado sujeto a destrucción y/o saqueo. Las modalidades por la que esto ocurre son variadas $\mathrm{y}$, frecuentemente, involucra a sus habitantes y sus donaciones testamentarias. Entre estos casos se encuentra el Perú, en el que se inició la depredación desde la llegada de los europeos en el siglo XVI y ha seguido un ritmo continuo hasta la actualidad. Aquí hacemos un breve recuento del destino de algunas obras de arte peruano antiguo y virreinal y de como su falta perjudica la identidad nacional.

\section{Palabras clave}

Obras de arte peruano antiguo. Virreinal perdidas/testamentos. donaciones/conflictos bélicos. Destrucción/ identidad. Patrimonio cultural.

\begin{abstract}
The artistic cultural heritage from countries which were invaded or faced war in any time of their history has been subject to destruction or pillage. The modes in which that has occurred are varied and, frequently, involved their inhabitants and their testamentary donations. Among those cases are the Peru, in which the predation has started since the arrival of the European, in the sixteenth century and has followed a steady pace until the present. Here is a brief recount of the destination some ancient and viceregal Peruvian artworks and how their absence damages the national identity.
\end{abstract}

\section{Keywords}

Lost Ancient. Viceregal Peruvian artworks/wills. Donations/wars. Destruction/identity. Cultural heritage. 
El 9 de diciembre de 1601 una temprana concertación da cuenta de una situación recurrente en el Perú: los artistas Mateo Pérez de Alesio ${ }^{1}$, su discípulo Cosme Ferrera Figueroa y Juan Ortiz, inscribieron notarialmente en Lima un acuerdo "En razón de la labor de Descubrimiento de una guaca tesoro/ o enterramiento que está en términos desde ciudad"(LOHMAN VILLENA, 1940, 23). No es previsible que los inspirara el afán arqueológico sino el aprovechamiento de las riquezas que aspiraron encontrar $\mathrm{y}$, con ello, el saqueo de patrimonio artístico, aunque entonces no se considerara como tal. Existieron leyes virreinales que ordenaban compartir los tesoros con la Corona española pero, para cumplirlas, generalmente había que fundir los objetos encontrados. En 1821, y en otro contexto político, el viajero escocés Basil Hall (1783-1844) llegó a Lima en el momento en el que se dilucidaba la presencia española en el Perú. Su relato es ameno y parco. Con precisión relata los dramáticos momentos que pasó la población alrededor del proceso de la independencia. En esa circunstancia pudo conocer a personajes de todas las clases sociales y tiendas políticas. Uno de ellos, al que describe elogiosamente como un "anciano español", de mucho prestigio e influencia en la ciudad por su buena disposición y atinados consejos, fue arrestado y finalmente deportado por los patriotas por conspiración a favor de los realistas. Hall fue a visitarlo durante su cautiverio que, aparentemente, fue el convento de San Francisco en Lima porque fueron dos frailes de esa Orden los que le habrían tendido la trampa que lo

\footnotetext{
${ }^{1}$ Notario Juan Bello, 1600-1602, fols. 52vto. Y 992. Pérez de Alesio fue un reconocido pintor de origen italiano considerado el promotor de la pintura peruana que trabajó para las más altas autoridades civiles y religiosas del Virreinato peruano. El término "descubrimiento" aquí debe entenderse como "identificación y saqueo". 
confinó en prisión. Allí encontró que “El cuarto en que se hallaba preso estaba adornado con cuadros antiguos, entre ellos uno de San Francisco, de Velásquez, que él [el anciano] había estado intentando adquirir de los frailes en la esperanza de que yo lo aceptase para colgarlo en la cámara de mi barco"(HALL, 1971, 269) ${ }^{2}$. El anónimo personaje español quería obsequiarle el cuadro al marino escocés y, con ello, respondía a una extendida percepción de la obra de arte en los territorios americanos: útil para quien la necesitara, de fácil apropiación y libre disposición. Pero no era solamente el patrimonio que pudiera considerarse "de ocupación" del que se podía disponer libremente.

El mismo testigo cuenta que cuando el 13 de diciembre del mismo año visitó a José de San Martín en la sede del gobierno, pudo ver la curiosa momia que la víspera había sido traída desde una aldea del norte de Lima,

La figura era de un hombre sentado en el suelo, con las rodillas casi tocando el mentón, los codos apretados a los costados, y las manos oprimiendo los pómulos. La boca entreabierta enseñaba dos filas de lindos dientes. El cuerpo, aunque encogido de modo extraordinario, tenía toda la apariencia humana, conservando la piel intacta, excepto en un hombro. En el semblante había una expresión de agonía muy claramente acusada.(256) .... [otras] Se habían encontrado generalmente en la posición arriba descripta, en pozos cavados en arena, de más de doce pies de profundidad...Sentada cerca del mismo sitio se encontró una figura de mujer con una criatura en brazos. La mujer se había convertido en polvo al ser expuesta al aire, pero la criatura que nos fue mostrada se mantenía entera. Estaba envuelta en tela de algodón, tejida con mucha habilidad y compuesta de variedad de brillantes colores y toda completamente nueva. También los trozos de tela que había usado la figura de mujer eran perfectos y las fibras absolutamente fuertes. Estos cuerpos

\footnotetext{
${ }^{2}$ Hall llegó a Lima en febrero de 1821 al mando del Conway, se marchó en agosto y regresó en diciembre. 
fueron desenterrados de una región del país donde jamás llueve, y la arena, por consiguiente, es tan perfectamente seca, que produce una absorción de la humedad tan rápida, que no permite la putrefacción.(HALL, 1971, 256257)

Ambos fardos, el del hombre y el de la mujer con el niño, seguramente con los textiles que los cubrían y los objetos que formaban los ajuares funerarios que por la descripción debieron provenir de la cultura Chancay, fueron enviados a Inglaterra en el Conway y entregados al Museo Británico, en esta ocasión por acción de los patriotas. ${ }^{3}$ Lamentablemente, añadido a la pérdida para el país de origen, los objetos de arte que acompañaban estos conjuntos funerarios siguen incorporados a las colecciones etnográficas de los museos obviándose los valores estéticos propios de las culturas que los produjeron, a pesar de haber sido reconocidos como obras de arte por numeroso estudios desde inicios del siglo $X X$.

Un revelador ejemplo en la misma época lo protagonizó el general José D. Espinar, secretario de Simón Bolívar, el 21 de marzo de 1824 al ordenar al coronel Andrés de los Reyes

Haga recoger y remitir inmediatamente a esta ciudad de Trujillo, a disposición del prefecto, todas las alhajas de oro y plata de todas las iglesias de su jurisdicción, [toda la costa de Lima] sin dejar en cada una de ellas más que la custodia, los cálices, las pátenas, las copas de dar la comunión y un incensario... De preferencia debe US. tomar las alhajas de las iglesias de Huacho, Huaura, Supe, Barranca, Sayán, Vilcahuaura y demás pueblos que estén más inmediatos a la frontera enemiga, y puedan ser ocupados por ellos...Reencarga S.E. una y mil veces la pronta remisión de

\footnotetext{
${ }^{3}$ En el catálogo en red del Museo Británico se encuentra un ejemplar donado por el capitán J.H. Gronow que podría ser el fardo de la mujer con el niño.

Revista do Programa de Pós-graduação em Arte da UnB 
todo el oro y plata de todas las iglesias de la prefectura de su mando (PAZ-SOLDÁN, 1921,141-142)

Como Reyes se excusó de cumplir la orden, fue destituido de su cargo y tomado preso por Bolívar. Esta no fue la única carta enviada en este sentido a otros funcionarios en la misma fecha y muestra que ambos bandos, independentista y monárquico, tuvieron interés en capturar los bienes patrimoniales muebles e inmuebles con alto valor adquisitivo para luego repartirlos entre sus allegados o comercializarlos. Sería un anacronismo pretender que en periodos históricos pretéritos se tuviera un concepto preciso de patrimonio cultural o artístico, en especial porque diversos sectores gubernamentales creyeron que los bienes públicos eran su propiedad particular. La experiencia demuestra que la liberalidad con la que trataban los objetos suntuosos y el destino que les dieron como especie de retribución o de prestigio se remonta a épocas tempranas. Pero paralela y paradójicamente, revela la indiferencia ante obras de arte que fueron consideradas de uso práctico orientadas a un fin determinado, sin valorarlas como artísticas por ninguno de los sectores involucrados ${ }^{4}$ Y aunque en la ocasión que señala Hall parece que los franciscanos no vendieron el Velásquez al "anciano español", posiblemente debió ser por su reconocida filiación realista; su condición momentánea de reo sin su anterior prestigio, y el compromiso de los religiosos para con los patriotas,

\footnotetext{
${ }^{4}$ Guillermo Ulriksen Becker, 1964, pp. 16-17, cuenta que había tenido a la vista en el convento agustino de Lima un "arrumadero" de imágenes con trozos policromados. Él lo atribuye a "barreras morales que impiden su total desaparecimiento (sic) y destrucción" pues ya había tenido una experiencia previa dos años antes en los que encontró esculturas no registradas y polvorientas en los escombros de lo que había sido el presbiterio. (p. 3) El historiador Héctor Schenone también le refirió que en el desván de un convento limeño había encontrado una imagen de valor. Estas experiencias confirman el descuido y el exclusivo valor utilitario que lamentablemente sectores de la Iglesia brindan a la obra de arte en cualquier lugar geográfico. 
porque en otras circunstancias no fueron tan celosos en defensa de obras que consideraron prescindibles, desdeñando su valor.

Hall relata sus experiencias en el momento en que los españoles habían sido conminados a abandonar el país si no suscribían la causa patriota. Algunos lo hicieron y partieron a la primera advertencia llevando sus bienes pero otros se negaron, por lo que meses después, "no menos de cuatrocientos españoles de las primeras familias y personas de las más ricas de Lima, fueron sacados de sus casas por la fuerza y marcharon a pie hasta El Callao", donde fueron embarcados hacia Chile. Inicialmente se confiscó el 50\% de sus caudales, luego la totalidad, de manera que en julio de 1822 "la ruina de los españoles pronto fue completa" (HALL, 1971, 263). Los bienes confiscados pasaron en propiedad a los grupos que en ese momento estaban en el poder, especialmente las obras de arte y de valor material que, posteriormente, en gran parte se perdieron.

El viajero francés Max Radiguet visitó varias dependencias religiosas limeñas (1841-1845), y entre ellas menciona el museo que existía en la iglesia de San Pedro, entonces administrado por la congregación de San Felipe Neri debido a la expulsión de los jesuitas. Allí observó 44 retratos de cuerpo entero de virreyes, obispos, funcionarios y generales "marchando a la guerra de la Independencia" y los objetos del Perú antiguo como "figurinas de oro y plata, diversos utensilios, frecuentemente de los mismos metales, ornamentos y joyas, tales como collares y pulseras, anillos y finas cosas de oro que servían de zarcillos; discos y medallas que colocaban en la boca de los cadáveres" y, junto a las piezas de cerámica, las momias aún cubiertas con sus mantos. (RADIGUET, 1971, cap. IV, 87, 88) También hizo un amplio recuento del 
legado pictórico en colecciones religiosas, públicas y privadas que afirma existían en todo el Perú. Señala que la cantidad de cuadros en los templos "sobrepasa a toda expectativa" y que "muchos particulares -sin mostrar por ellos mucha vanidad- poseen colecciones de las que, ciertamente, harían exhibición nuestros banqueros millonarios". Puede imaginarse la gran cantidad de ellas considerando además,

Las pinturas destruidas por los temblores, laceradas durante las discordias civiles, en las que la negligencia ha dejado caer hechas polvo, y sobre todo en las que han sido vendidas a los extranjeros (que no eran sin duda las peores) se comprenderá que mercado fue, para los talleres de los siglos diecisiete y dieciocho, el rico y floreciente Perú de los Virreyes. (RADIGUET, 1971, cap. IV, 108)

En su comentario, que evidencia el expolio sistemático, extiende su admiración sobre la colección particular del marques de Santa María que afirma "podría sin perjuicio, tener lugar en nuestros grandes museos", pues estaban representadas todas las escuelas europeas (RADIGUET, 1971, Cap. VII, nota 1). Años después, la llamada Guerra del Pacífico (1879-1883) significó la destrucción tanto como el saqueo de obras de arte que fueron llevadas a Chile. Varias circunstancias, como el traslado en el equipaje de sus propietarios o compradores, llevaron piezas fuera del país lo que ha significado la pérdida de valioso patrimonio artístico y arqueológico.

En este contexto y por variadas razones se añade otra circunstancia, los naufragios que significaron la desaparición en el trayecto a Europa de objetos de arte procedentes de América en especial, aunque no exclusivamente, de joyería. La inexistencia de datos útiles para recomponer el momento artístico al que perteneció un objeto, adicional al 
deterioro y descuido en su uso, tiene como razones la venta; la reutilización de algunas de sus partes; o su fundición para recuperar el material. Hay ejemplos a uno y otro lado del Atlántico. Un caso que se menciona es el joyel del Real Monasterio de Guadalupe en España que recibió deslumbrantes donaciones de viajeros a Indias del siglo XVI. Estas piezas fueron manufacturadas en América y, de exixtir, servirían de importante fuente de conocimiento acerca del ejercicio artístico local, de la condición técnica y artística de la orfebrería y de las preferencias iconográficas de la época. Entre los casos documentados está el del virrey del Perú Francisco de Toledo que envió tres figuras de plata que representaban a los Reyes Magos; y el de su Secretario, que en 1619 agregó un trono de plata para la Virgen; en 1642 un devoto de Extremadura contribuyó desde Lima con candelabros de plata; un Oidor de la Audiencia limeña envió una cruz de cristal y un crucifijo. La referencia que existe sobre algunas obras se encuentra en el Libro de dibujos del joyel de Nuestra Señora o Inventario del Joyel de Nuestra Señora de Guadalupe de fines del siglo XVIII, (apud ARBEZETA, 1999, 430-433) pero su precisión es cuestionada al comparar los documentos y dibujos que las describen. ${ }^{5}$ Puede comprenderse la incompatibilidad debido, en primer lugar, a la capacidad del dibujante pero igualmente al tiempo transcurrido entre la entrega de las piezas y su documentación, cuando pudieron sufrir deterioro o ser modificadas, lo que convierte la descripción en anécdota referencial. Los indianos enviaron cuantiosas fortunas en joyas a su tierra natal (cálices, lámparas votivas, juegos de altar, incensarios, coronas,

\footnotetext{
${ }^{5}$ Esto sucede con frecuencia en las écfrasis utilizadas por la historia del arte como fuente para reconstruir objetos perdidos a la observación. Constituyen una información general que dan una pauta pero difícilmente permiten la reconstrucción precisa.

Revista do Programa de Pós-graduação em Arte da UnB 
rosarios, etc.) algunas de las que han sido consideradas ejemplares únicos por su manufactura, con "ese toque personal que desarrollaron todas y cada una de las platerías peruanas" (PÉREZ MORERA, 2011, 29). También queda sujeta a especulación la procedencia de las joyas de los rescates de naufragios, como el de Nuestra Señora de Atocha de 1622 que transportó mercancías desde el puerto limeño de El Callao. A pesar de que se reconoce la alta calificación de los orfebres europeos que emigraron y se destaca la alta calificación indígena en este arte, excepcionalmente se admite que el preciosismo en la factura de las obras exportadas son obra americana, salvo que el tamaño de las gemas, el peso específico del metal o la iconografía lo haga evidente. Un caso entre otros de un indígena con oficio de platero en Lima aparece en el testamento de Antón Guallaxima en 1579 cuando deja constancia que "tiene en su poder Pedro indio platero...un collar de oro que le di para aderezar que valía ocho pesos." ${ }^{6}$ Muy tempranamente este estamento aplicó su capacitación orfebre en el mercado virreinal, hecho relevante considerando que las normas establecían que este oficio debían ejercerlo solamente lo españoles.

El uso de joyas como medio de pago que las expuso a transformación y pérdida aparece en un concierto de 1590 en el que Lorenzo Balbi vende un esclavo negro al platero en oro Pedro Rodríguez y recibe a cambio "dos joyas de oro que son una hechura de un caballo marino con una figura de mujer encima que todo es de oro y esmeraldas y piedras con una cadenita de que está pendiente y una sortija de oro y esmeraldas que todo fue apreciado oro y esmeraldas y hechura", por los

${ }^{6}$ Ante Marcos Franco de Esquivel. Lima, 24 de agosto de 1574. Fol. 383.AGN 
400 pesos que costó el esclavo. ${ }^{7}$ Otros casos por los que las obras de orfebrería corren el riego de perderse fue por haberlas entregado en prenda para préstamos que no es seguro hayan sido saldados. En su testamento del 14 de abril de 1608 el empedrador portugués Alonso de Ávila declara haber empeñado "un punzón de oro...y un salero de plata blanco sin dorar...una lagartija de oro...una espada mía y un frasquillo de plata y unos corales con almirez y una cruz de oro...una sarta de perlas...y unos zarcillos de oro con unos brochecillos de esmeralda...un cintillo de oro pequeño...unos zarcillos de oro y una sortija verde...una gargantilla de perlas con unas bermelletas..." ${ }^{8}$, suponemos que todo ello propiedad de su esposa, a quien deja de albacea, porque también empeñó trajes de mujer de raso de Castilla, de terciopelo azul y terciopelo negro. ${ }^{9}$ Otra modalidad fue el envío a España de alhajas y dinero, como estipuló Antonio Portocarrero Laso de la Vega, conde de Moncloa, virrey del Perú fallecido en Lima. (EGUIGUREN, 1946, 244)

El bagaje de obra americana en Europa y América se incrementa porque los particulares mostraban su generosidad por vía testamentaria a favor, prioritariamente, de las devociones religiosas bajo custodia de la Iglesia. La marquesa de Rocafuerte, Constanza Costilla de Valverde, dejó en febrero de 1762 a la imagen de Nuestra Señora de la Concepción en el Cusco,

Un par de zarcillos de oro, grandes, de tres pendientes de perlas gruesas, sin pasar, que ambos tienen diez perlas, con las de los broqueles y 78 diamantes regulares, tablas y rosas ...un faldellín, que tiene, nuevo tisú de plata y un

\footnotetext{
${ }^{7}$ Notario: Bartolomé de Torquemada, Lima 12 de abril de 1590. Folio 2015vta. AGN.

${ }^{8}$ Bermelleta o vermelleta, tipo de granate color rojo carmesí, ligeramente anaranjado y más brillante que otras variedades. MIRO, 1870,149.

9 Notario: Cristóbal de Barrios. Lima 14 de abril de 1608: Folio 505. AGN 
jubón de lo mismo, con franjas de oro, anchas, para que se haga un vestido...un cinto de oro, con diamantes al medio y 164 diamantes tablas pequeños y dos grandes, con su calabaza de perlas grandes en el remate del cinto (CORNEJO BOURONCLE, 1960, 303-304)

Además, entregó un Santo Cristo de oro mediano con cadena de oro, una cajita de oro y un calentador grande de plata como retribución por pasadas acciones de la monja Petronila de la Presentación. Se afirma que todo lo mencionado desapareció, o por lo menos no se encontraba en su tiempo en el lugar al que había sido destinado. Pero el patrimonio de la marquesa era mucho mayor. En la relación de joyas de su legado figura

1 par de baulitos de perlas, con 128, 2 botones de perlas menudas; 1 relicario grande de oro con 107 diamantes tablas, entre pequeños y grandes, con cinco perlas gruesas y cadena larga; 1 par de candados de oro con 30 perlas medianas y las cuatro del medio grandes; dos aguacates de esmeraldas grandes; 1 rosario de cuentas de perlas, con 6 trechos, 31 cuentas y 6 botones y su cruz de diamantes; 1 par de manillos de corales grandes, con tres botones de perlas; 1 rosario de sahumerio, con esmalte de concha de perlas y cruz de concha y perla; 1 par de orejeras de oro con esmalte azul y blanco con una perla grande al medio; 1 par de manillos de Tumbaca con sobrepuestos de diamantes grandes; 2 cabezas de polizón, grandes, cubiertos de diamantes; 4 sortijas hermanas de cabeza de turco, con diamantes, con 9 cada una; 1augador de perlas grandes con sus trechos de diamantes, con lazo grande de diamantes y cruz de diamantes; 1 sortija ... con nueve diamantes tablas (CORNEJO BOURONCLE, 1960, 305)

Considerando este caso entre otros muchos que fueron enviados al extranjero, el estudioso puede intentar reconstruir las piezas mencionadas vinculándolas a las que podrían haber sobrevivido de otros legados, pero tendría dificultad para datarlas y referirlas a una manufactura espacio 
temporal específica. La posibilidad de cotejar la explicación del diseño de las joyas con objetos preservados no lograría la seguridad que requiere una investigación, debido a la falta de precisión en la descripción. ${ }^{10}$ Tampoco puede conocerse la tendencia estilística del momento, la historia menestral, los artistas que realizaron la obra o la fecha de su factura.

Considerando las limitaciones de la falta de precisión, puede encontrarse la actitud ante los objetos de orfebrería en algunos testamentos. Rafael de Rivera, hijo de Nicolás de Rivera primer Alcalde limeño y pionero en la tierra, otorgó testamento el 24 de junio de 1586 en el que señala obligaciones con artífices como "un platero que se dice Cortés" al que le había encargado una cadena de oro; unas tablillas de plata entregadas al carpintero Juan Cano para asentarlas en madera; un candelabro de plata que lo dio para pesar a un platero vecino de Cortés del que no recordaba el nombre y que se recogiera unas espuelas de plata dorada al platero Juan Ruiz. ${ }^{11}$ El otorgante olvidó los nombres, en el primer caso anota que tampoco se acordaba haber entregado el dinero del encargo, lo que señala la prodigalidad con la que se hacía el gasto, el escaso interés en el pedido mismo y la indiferencia con la que se hacía la inversión, además del exceso de fortuna de los clientes.

Entre las causas de pérdida o deterioro de patrimonio están los terremotos. El del 20 de octubre de 1687 fue particularmente destructivo

10 Esta indiferencia en detallar pormenorizadamente las piezas advierte de varios aspectos que también son interesantes para el estudio, aunque marginalmente significativos: el escaso interés en las obras de orfebrería; su relativa calidad formal que no llegó a impresionar al observador o la voluntad expresa de evitar su identificación posterior. Esto informa sobre el declarante así como la tendencia del gusto de una época. También hay que considerar que en ocasiones las joyas enviadas tuvieron el objetivo de encubrir el envío del metal pues su destino era ser fundidas para recuperarlo.

${ }_{11}$ Ante Esteban Pérez, 24 de junio 1586: folio № 681, AGN. Se refiere al platero Francisco Cortés. 
para las dependencias agustinas. ${ }^{12}$ Entre otras desgracias, la campana derribó la cúpula, atravesó dos techos "fuertemente enmaderados, rompió la bóveda y se hundió dos varas en la capilla de San Miguel". Como consecuencia "se destruyeron las pinturas de Medoro, Alexio (sic) y de nuestro insigne Bejarano" que cubrían toda la iglesia, especialmente el arco toral $\mathrm{y}$ el coro bajo donde estaba pintada la gloria y una representación de san Agustín de Angelino Medoro. A ello se sumó el saqueo que con la pérdida de sus dependencias, obligó a los frailes a abandonar la ciudad (VÁSQUEZ CARCERÓN, 1725, Lib. III, cap. 1, apud MONASTERIO, 1908, 11). ${ }^{13}$ Vinculada a la pérdida fortuita de patrimonio también se encuentran las decisiones que en algún momento de su historia tomaron las Órdenes religiosas. En ocasiones derivan de compromisos

\footnotetext{
12 La devastación empeoró por los dos sismos consecutivos que sufrió la ciudad considerada "la más opulenta de este Reino, Corte del, era la más bien adornada y alhajada, y tan precioso el menaje que de sus templos y casas, que no hay número ni guarismo que ajuste el valor de lo que importaba su precio". En la Información que hizo el Cabildo, Justicia y Rejimiento (sic) ante el Teniente del Cabildo Diego Fernández Montaño, se consigna que las pérdidas sufridas por la población religiosa y civil era incalculable "pues raro ha sido templo o casa particular de donde se haya sacado cosa que valga quinientos pesos, diciendo mas los prácticos que en retablos de iglesias y lienzos, y diferentes ornatos de colgaduras, espejos y láminas, estrados, escaparates y escritorios, sillas y demás alhajas ordinarias, se habrán perdido más de veinte millones". ANGULO, 1939, 9. Los franciscanos sufrieron, adicionalmente, la destrucción de su templo en 1656 por fallas estructurales. Fray Miguel SUÁREZ DE FIGUEROA OFM en su Templo de N. Grande Patriarca San Francisco de la Provincia de los Doze (sic) Apóstoles del Perú en la Ciudad de los Reyes arruinado, restaurado, y engrandecido de la Providencia Divina. (Lima, 1675: folio 3 ), proporciona detallado recuento del desastre y anota que quedaron "quebrantados los altares, rotos los retablos y ornamentos, desoladas las aras", lo que implica la pérdida de los lienzos y pinturas murales que previamente mencionó en su Coronica de la religiosissima provincia de los doze (sic) apóstoles del Perú. (Lima, 1651:Libro III, Cap. VII). Estas pérdidas afectaron notablemente el patrimonio artístico limeño del siglo XVII.

${ }^{13}$ El escrito inédito de Vásquez tiene dos tomos. Vásquez fue criollo y Padre Maestro. En el Capítulo de 1721 le fue encargado continuar la crónica de Calancha y Torres desde 1657 a 1725. Ha permanecido inédita porque, en opinión de algunos agustinos, no merecía publicarse por su lenguaje alambicado, la falta de precisión en los datos y fechas aunque, para aspectos vinculados a la labor misional es, al parecer, imprescindible. VILLAREJO, 1975, 265. Monasterio toma las fechas.
} 
sociales que no todas sus autoridades pudieron eludir. Una insinuación en este sentido la hizo Fray Juan de Benavides, Ministro del Tribunal de la Inquisición y Sacristán franciscano cuando, en alabanza al excelente gobierno del Comisario General fray Luis Cervela, declaró, “(exponiéndose por nuestras conveniencias y por defender las preciosas alhajas de nuestros Conventos, de los préstamos, que comúnmente las destruyen) a la indignación de los poderosos"(SUÁREZ DE FIGUEROA, 1675, s/fol). Especialmente las exigencias provenían de las autoridades o de quienes por ser benefactores pudieron haber invocado un derecho que, en este caso, no fue satisfecho. Otras causas derivan de dificultades económicas imprevistas, como las consecuencias no superadas de un terremoto tan devastador como el de 1746. El 22 de abril de 1802 el provincial de la Orden de San Agustín en Lima, Manuel Azereto (18011805), pidió autorización para solicitar un préstamo para culminar las obras de la iglesia y encargar un retablo mayor nuevo porque el otro estaba en ruinas (MONASTERIO, 1908, 10). Proponía vender los muchos marcos de plata "de chafalonía" y "la corona de perlas que usaba el santo patriarca el día de su fiesta por faltarle varias perlas y luego le faltarían más y no serviría, para darle otra de plata dorada esmaltada con algunas piedras para mejor duración y lo restante para los fines insinuados. También se harían nuevos el altar de Santa Rita y otros" (MONASTERIO, 1908, 31). Obsérvese que el argumento es deshacerse de piezas de relativo valor, así como de una joya que debido a su deterioro le pareció más adecuado cambiarla por una factura más reciente en lugar de restaurarla. La postura que se evidencia puede extenderse a otras congregaciones y a otros objetos que fueron rematados para sustituirlos por aquellos que la 
moda dictaba como más adecuados. La tendencia fue y es permanente, refleja la percepción de los diversos receptores respecto a obras de valor artístico. Su condición se reduce a su aspecto general óptimo y a su uso, el cambio o sustitución obedece a necesidades apartadas de valores estéticos, no se insertan en una secuencia de valor histórico artístico.

Pero en otras situaciones podría vislumbrarse cierto escrúpulo para desprenderse de obras consideradas valiosas, además de útiles. Nuevas dificultades pusieron a prueba el patrimonio agustino en el siglo XIX ante la incertidumbre por la seguridad del reino o la posterior lucha por la independencia, cuando inevitablemente sufrieron las propiedades y los recursos de la Orden, como de las otras en el Perú, a instancias de la administración virreinal. Por la inminente aparición de corsarios ingleses en la costa, el 18 de septiembre de 1807 el virrey Abascal convocó a la ciudadanía. Debía repararse las murallas y a los agustinos les tocó el baluarte que se "halla junto a la portada de San Jacinto, bajo el número siete y para cuyo reparo su costo no podía bajar de 4, 359 pesos", según una tasación que el convento no podía sufragar (MONASTERIO, 1908, 32). El Definitorio resolvió "vender la plata labrada que fuese menos visible y que menos falta hiciese para los destinos y culto de la Iglesia". Las especies numeradas, que no se detalla, sumaron 2, 271 pesos y real y medio. Para suplir su falta los religiosos debieron solicitar apoyo a los conventos de las provincias. (MONASTERIO, 1908, 33) Era plata labrada que, aunque poco visible, debió ser representativa del estilo predominante en el tiempo de su factura. En este caso los frailes parecen dolerse de la entrega y no estar dispuestos a inmolar la totalidad de su patrimonio.

Los dominicos se enfrentaron a la misma circunstancia Muchos de

$$
\begin{array}{r}
\text { Revista do Programa de Pós-graduação em Arte da UnB } \\
\text { V. 16, } \mathbf{n}^{0} 1 / \text { janeiro-junho de } 2017 \\
\text { Brasília } \\
\text { ISSN- 1518-5494 } \\
\text { ISSN (versão eletrônica): 2447-2484 }
\end{array}
$$


los miembros de la orden decidieron retornar a Europa cuando el país aún se encontraba convulsionado por el proceso de la Independencia, a pesar de que el Capítulo aprobó medidas a favor de los grupos libertarios. Precisamente, para apoyar la causa patriota, el 13 de abril de 1822 el Provincial Jerónimo Cavero "abogaba y obtenía que la comunidad diera la plata labrada de la iglesia de santo Domingo para sostener la causa patriota", con el argumento de que debían adelantarse a que se repitiese el saqueo que habían perpetrado anteriormente los realistas (ARÉVALO, 1970, 237). La justificación señala que en la época de la administración española el saqueo fue indiscriminado, posiblemente dirigido expresamente a las obras más valiosas, por lo que en esa nueva ocasión era preferible que la propia congregación seleccionara lo que estaba dispuesta a entregar. No se especifica la condición ni procedencia de estas piezas pero entre ellas estuvieron las columnas de plata que la Universidad de San Marcos había ofrecido como regalo en 1786 para el retablo de Santa Rosa de Lima, Patrona de la Institución, que estaba situado en la iglesia de Nuestra Señora del Rosario. ${ }^{14}$

La catedral limeña también fue objeto de requisa. Tal como señala Radiguet "los candelabros, las lámparas y los floreros sagrados de la Catedral, eran de plata y oro, y enriquecidos con una profusión de pedrerías; pero fue obligada a aportar a la causa de la Independencia con una parte de las riquezas; así fue como el peso de la plata recolectada por el gobierno, en las diferentes Iglesias, durante los años 1819, 1820 y 1821, solamente sobrepasó, se asegura, las tres mil libras de peso." (RADIGUET,

\footnotetext{
${ }^{14}$ Las columnas databan de 1786 cuando la Universidad de San Marcos donó 4,000 pesos para forrar en plata las columnas del retablo que en ese momento construía Juan Palomino. Finalmente su costo se elevó a 5,997 pesos. UGARTE CHAMORRO, 1986. 
1971, CAP. VII, 193) Fue también el caso de la exigencia de Simón Bolívar en 1824, mencionadas antes. No tanto la cantidad como la calidad de los objetos, que fueron más de los que se señala, da a entender su valor pues el templo mayor limeño fue lugar de coincidencia de valiosas donaciones y en el que desarrollaron su obra los más importantes artistas. Un patrimonio lamentablemente perdido.

Un ejemplo cercano refiere a propietarios particulares. En la Exposición Arte Italiano en el Perú que realizó en Instituto Cultural ÍtaloPeruano en el Museo de Arte Italiano de Lima, inaugurada el 17 de diciembre de 1953, se consigna el retrato de fray Luis López "catedrático de Vísperas de Sta. Teología, año 1577. Y Obispo de Popayán y Quito y Arzobispo de Los Charcas" de Mateo Perez de Alesio (1547-1600?), una de las 75 obras que dejó el pintor en Lima cuando regresó a Roma. El anónimo autor de la reseña afirma que de la obra, de 114 por $150 \mathrm{~cm}$. propiedad de la Universidad Nacional Mayor de San Marcos, "casi nada queda: todo destrozado, o exportado, o desconocido" pero, además, que una persona "mutiló el lienzo, cortó la parte alta del escudo de Fray Luis para adaptarlo...cuando Fray Luis fue nombrado Catedrático de San Marcos." (INSTITUTO CULTURAL ÍTALO-PERUANO Y MUSEO DE ARTE ITALIANO, 1953, 13) Entre la cantidad y calidad de las pinturas de origen europeo que se expusieron en esta ocasión aparece una de Angelino Medoro, el pintor que con Pérez de Alesio y Bitti se consideran iniciadores de la pintura peruana en el siglo XVII. Estas obras estaban en colecciones particulares como la Ortiz de Zevallos y Tagle que se deshizo en 1914 y en parte pasó a la colección Hoblitz Elle en Dallas (USA), de acuerdo a la información que en 1873 otorgó Yeckel, e inició la etapa de 
nuevos coleccionistas como Rivera Schereiber; Moreyra Paz Soldán o Lavalle-Ganoza (STASTNY, 1970), así como la posterior salida y ocasional subasta internacional de las piezas. Junto con las extranjeras, las colecciones reunían obras peruanas de distintas épocas que, finalmente, sufrieron el mismo destino.

Detrás de los ejemplos mencionados destaca un aspecto que contribuye en mucho a la comprensión de la producción de los objetos de arte virreinales y su historia futura: cada obra de arte tiene prefigurado su destino por el mercado, las circunstancias de la adquisición o de los encargos, la posición social del cliente y su relación con el artista, así como la ocasión en la que se adquiere. Importante es la posición del cliente ante la posibilidad de que auspiciara, advirtiéndolo o no, posturas políticamente inconvenientes porque era él quien decidía contratar a determinado artista así como el aspecto final del producto. En el siglo XVI ya era evidente los problemas que podían derivarse de esta situación, por lo que el virrey Francisco de Toledo determinó

y por cuanto dichos indios, soy informado que en mucha parte de las obras que hacen pintan [representan] sus ídolos, ordeno y mando que el dicho veedor tenga especial cuidado de que en las obras que se labrasen de oro y plata no se pongan pinturas si no fuere aquellas que las mismas partes expresamente pidieren y dieren memoria. (LOHMANN VILLENA, 1986, Tomo I, 207). ${ }^{15}$

El derecho del cliente fue reconocido como definitivo para fijar lo propio o lo impropio de una representación, así como estableció que no podría ejercer este derecho de manera amplia o de enfrentamiento. La mención a ídolos, como específica de la propuesta indígena, marginaba al

${ }^{15}$ Ordenanzas para la ciudad del Cuzco y sus términos. Checacupe, 18 de octubre de 1572, Título XXVII (205-209). 
europeo y advertía al indígena acerca de las consecuencias posibles de una decisión apresurada y entusiasta por refrendar su procedencia cultural aunque fuera disimuladamente. Los objetos con iconografía indígena predominante estaban expuestos a desaparecer, a pesar de ello, en obras virreinales que se han recuperado aparece más o menos manifiesta su presencia en la iconografía, o en la particular manera de organizar la composición de motivos en la pieza, un detalle que informa de su procedencia y permite el reconocimiento de la habilidad local.

¿Por qué afecta de manera significativa constatar la pérdida del legado patrimonial de una época o un país?¿Por qué es fundamental intentar reconstruir las obras de arte lo más próximo a su estado original? ¿Por qué es importante este hecho y otros que se vinculan a objetos de arte? Porque coinciden en ellos factores como: clientes y receptores; donantes y sus beneficiarios; artistas creadores y sociedades identificadas con sus obras; que de existir los objetos permitirían conocerlas así como a los actores en ellas, porque posibilitarían reconstruir la historia del arte de un tiempo y espacio geográfico determinados, incluso sin que tuviera que recurrirse a fuente distinta a las obras mismas. Son muchos los elementos que intervienen en este dinámico y complejo proceso que conduce la vida e historia de la obra de arte, y que configura la historia del arte como disciplina, fuente indispensable para definir los condicionamientos y características de una nación y su cultura. Los pueblos se reconocen en sus obras, negarles el derecho mediante el ocultamiento o la destrucción deliberada; ignorar la procedencia de una pieza o, conociéndola, exponerla fuera de su contexto en un lugar ajeno al lugar de su producción o distinto a la comprensión de su valor estético, afectan ese 
reconocimiento, transforma lo propio en extraño, anula la identificación que merece la cultura productora.

Existe una legislación mundial para proteger el patrimonio artístico de los países que no ha disuadido el tráfico ilegal porque, lamentablemente, permanecen los clientes que, lejos de apreciarlas, las adquieren por su valor comercial. Aceptando que podrían ser preservadas y cuidadas adecuadamente en colecciones extranjeras, las solicitudes de los países por repatriar obras de arte llevan implícita la necesidad de recuperar signos de identidad y de orgullo nacionales. Por la misma razón se justifica la queja cuando, mientras esto se resuelve, las obras son expuestas fuera de contexto en zonas museísticas etnográficas y no artísticas; o se almacenan en los depósitos imposibilitando todo tipo de acceso a su estudio. Es necesario que se comprenda la posición del afectado para sensibilizar a los adquirientes y resolver este milenario problema.

\section{Referencias}

\section{ARCHIVO GENERAL DE LA NACIÓN (AGN)}

ANGULO, Domingo OP. El terremoto del año de 1687. Revista del Archivo Nacional del Perú. Lima, enero-junio, Tomo XII, Entrega I, 1939. INFORMACIÓN que hizo el Cabildo, Justicia y Rejimiento (sic) ante el Teniente del Cabildo Diego Fernández Montaño.

ARBEZETA, Letizia. La joyería: manifestación suntuaria de los dos mundos. El oro y la plata de las Indias en la época de los Austrias. Madrid, Fundación ICO, 1999, 425-450.

ARÉVALO, José María O.P. Los dominicos en el Perú (visión histórica). Lima: Imprenta Editorial San Antonio 1970. 
CORNEJO BOURONCLE, Jorge. Derroteros de arte cusqueño datos para una historia del arte en el Perú. Cuzco: Ediciones Inca, 1960.

EGUIGUREN, Luis Antonio. Leyendas y curiosidades de la historia nacional. Miscelánea. $2^{\underline{a}}$ tomo de la colección Calles de Lima. Lima: 1945.

HALL, Basil. Viaje a Chile, Perú y México 1820,1821 y 1822: Extracts from a journal writen in the coast of Chile, Peru $\mathcal{E}$ Mexico in the years 1820-1822. (2 vols.) Edinburg, A. Constable and Co., 1824 (2da ed 1825), En: NÚÑEZ HAGUE, Estuardo, (Estudio preliminar y notas), Relaciones de Viajeros, Lima: Colección documental de la Independencia del Perú, Tomo XXVII, volumen 1, 1971, 199-268.

INSTITUTO CULTURAL ÍTALO-PERUANO y Museo de Arte Italiano. Exposición Retrospectiva de Arte Italiano en el Perú. Lima: 1953.

LOHMANN VILLENA, Guillermo. Noticias inéditas para ilustrar la Historia de las Bellas Artes en Lima durante los siglos XVI y XVII. Revista Histórica, Órgano del Instituto Histórico del Perú, tomo XIII, Lima: 1940, 5-32.

LOHMANN VILLENA, Guillermo (Introducción); María Justina SARABIA VIEJO (Transcripción).Francisco de Toledo. Disposiciones gubernativas para el virreinato del Perú. 1569-1574. Sevilla: Escuela de Estudios Hispano-americanos, CSIC, Monte de Piedad y Caja de Ahorros de Sevilla,1986.

MIRO, José Ignacio. Estudio de las piedras preciosas. Su historia y caracteres en bruto y labradas con la descripción de las joyas más notables de la corona de España y del Monasterio del Escorial. Madrid: Imprenta a cargo de C. Moro, 1870.

MONASTERIO, Ignacio O.S.A. Recuerdo de la inauguración del templo de San Agustín de Lima. Lima: Imprenta de E. Moreno, 1908.

PAZ-SOLDÁN, Juan Pedro. Cartas históricas del Perú. Correspondencia de los generales San Martín, Bolívar, Sucre, La Mar, Torre Tagle, Correa, Guido, Necochea, Otero, Heres, La Fuente, Beindoaga, etc. Segunda serie. Recopilada y anotada. Lima: Librería e Imprenta Gil, 1921.

PÉREZ MORERA, Jesús. Arte, devoción y fortuna. Platería americana en Canarias Occidentales. Catálogo, San Cristóbal de la Laguna: 2011. 
RADIGUET, Max. Lima y la sociedad peruana. Estudio preliminar: Estuardo Núñez. Traducción: Catalina Recavarren Ulloa. Lima: Biblioteca Nacional del Perú: 1971.

STASTNY, Francisco. La colección Ortiz de Zevallos. La Prensa, Lima: 26 de febrero 1970.

SUAREZ DE FIGUEROA, Miguel. OFM. Templo de N. Grande Patriarca San Francisco de la Provincia de los Doze (sic) Apóstoles del Perú en la Ciudad de los Reyes arruinado restaurado, y engrandecido de la Providencia Divina. Lima: 1675.s/fol.

UGARTE CHAMORRO, Guillermo. Santa Rosa Patrona de la Universidad de San Marcos. El Comercio, Lima: 17 de junio, 1986.

ULRIKSEN BECKER, Guillermo Hallazgo de 40 esculturas "platerescas" en la antigua contrasacristía agustiniana de Lima. Santiago e Chile: Universidad de Chile, Instituto de Teoría e Historia de la Arquitectura, 1964.

VÁZQUEZ GARCERÓN, Juan Teodoro. Crónica Agustiniana de esta Provincia del Perú de N.P.S. Agustín, etc (1725), Inédita, apud, MONASTERIO 1908

VILLAREJO, Avencio O.S.A. Los agustinos en el Perú (1548-1965), Lima: Editorial Ausonia, S.A., 1975.

YECKEL, Bernardo María. Gran galería de pinturas antiguas. Lima: 1873. 